\title{
Relational cohesion between users and smart voice assistants
}

\author{
Blanca Hernández-Ortega \\ Department of Marketing, Faculty of Business and Economics, Institute on Employment, Digital Society and Sustainability (IEDIS), \\ University of Zaragoza, Zaragoza, Spain \\ Foaquin Aldas-Manzano \\ Department of Marketing, University of Valencia, Valencia, Spain and \\ Instituto Valenciano de Investigaciones Economicas, Valencia, Spain, and \\ Ivani Ferreira \\ Instituto Federal De Educação Ciência E Tecnologia Do Paraná, Curitiba, Brazil
}

\begin{abstract}
Purpose - This study aims to examine users' affective relationships with smart voice assistants (SVAs) and aims to analyze how these relationships explain user engagement behaviors toward the brands of SVAs. Drawing on relational cohesion theory, it proposes that cohesion between users and SVAs influences brand engagement behaviors, that is, continuing purchasing other products of the brand, providing knowledge to the brand and referring the brand.

Design/methodology/approach - Data from a survey of 717 US regular SVA users confirm the validity of the measurement scales and provide the input for the covariance-based structural equation modeling.

Findings - The results demonstrate that frequent user-SVA interactions evoke positive emotions, which encourage cohesive relationships. Pleasured-satisfaction and interest emerge as strong emotions. Moreover, relational cohesion between users and SVAs promotes engagement with the brand of the assistant.

Originality/value - This paper applies an interpersonal approach in a context that, to date, has been examined from a predominantly technological perspective. It shows that users develop positive emotions toward smart technologies through their interactions, and establishes the importance of building affective relationships. To the best of the authors' knowledge, this is the first study to analyze cohesion between users and smart technologies and to examine the effect of this cohesion on user engagement with the brand.
\end{abstract}

Keywords Relationship marketing, Artificial intelligence, Customer engagement, Technology and service, Smart voice assistants, Relational cohesion, Engagement behaviors, Positive emotions, Interactions

Paper type Research paper

\section{Introduction}

The emergence and rise of smart technologies have created new forms of services that have transformed traditional offerings and the way that firms relate to their customers (Chouk and Mani, 2019; Ostrom et al., 2015; Park et al., 2016). These services, named smart services, integrate technology and data to anticipate and fulfill customer needs at specific times and/or locations, based on changing customer feedback and circumstances (Kabadayi et al., 2019). So, technologies such as smartphones, artificial intelligence, robotics, text mining, the internet of things, digital media, virtual reality and augmented reality, give rise to new forms of encounters that condition the management of relationships (Čaić et al., 2019; Huang and Rust, 2018; Gummerus et al., 2017; Kunz et al., 2019).

The current issue and full text archive of this journal is available on Emerald Insight at: https://www.emerald.com/insight/0887-6045.htm

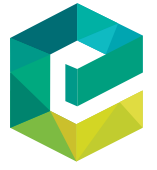

Journal of Services Marketing

(C) Emerald Publishing Limited [ISSN 0887-6045]

[DOI 10.1108/JSM-07-2020-0286]
Although smart services can take a big variety of forms, smart voice assistants (SVAs) are positioned as dominant services.

SVAs are software agents that rely on voice commands supported by artificial intelligence, natural language processing techniques and machine learning, to assimilate, understand and respond to users' demands (Hoy, 2018; Pal et al., 2020). They have the capacity of acting like actual human assistants, offering professional, technical and social services that individuals require in their daily lives (Santos et al., 2016; Yang and Lee, 2019). SVAs can provide users with the requested

\footnotetext{
The authors appreciate the valuable comments and suggestions made by the editors and the reviewers throughout the review process. They are also grateful for the support provided by the Spanish Government PID2020118425RB-I00/AEI/10.13039/501100011033; CÁTEDRA INTEGRA, Strategy and Technology, University of Zaragoza, and the Government of Aragon and the European Regional Development Fund (GENERES, Group S54).
}

Received 15 July 2020

Revised 2 February 2021

29 June 2021

7 August 2021

24 August 2021

Accepted 28 August 2021 
information, such as weather updates or specific questions, and also perform several tasks for users, such as turning lights on/ off, controlling networked devices and placing online shopping orders (Feine et al., 2019; Liao et al., 2019; Lopatovska et al., 2018). Thus, SVAs emerge as sophisticated service platforms that have changed the way that consumers interact, decide and behave, so they should be studied keenly (De Keyser et al., 2019). Globally, the most popular SVAs and brands are Siri from Apple, Alexa from Amazon, Cortana from Microsoft and Google Assistant.

Although the literature related to SVAs is still young, two main categories can be placed. The first category is focused on the technological attributes of SVAs and explores the effect of their voice, language, security and privacy, etc. (Davenport et al., 2020; Pagani et al., 2019; Poushneh, 2021). The second category analyzes SVAs from the point of view of users, examining their perceptions, motivations, gratifications and behavioral intentions (McLean and Osei-Frimpong, 2019; Shin and Park, 2017). These categories have in common that they apply one-sided approaches that were initially elaborated to explore previous technologies. So, they take for granted that the findings obtained for "classic" technologies, as computers or the internet, can be applied to address smart technologies. Nevertheless, in this new context, only a few works have studied relationships between users and SVAs, taking into account that smart capabilities may change the rules of the game (Biele et al., 2019; Pagani et al., 2019).

In contrast to previous research, we argue that smart technologies are no longer mere tools that allow users to communicate with others and obtain information but become main actors that interrelate with users in an interpersonal way. Specifically, we propose that SVAs introduce a new case of relationship marketing in services, so understanding interactions between parties is crucial to advance in research. During these interactions, SVAs apply cognitive capabilities to process information and accumulate knowledge, personalizing experiences, providing solutions and creating value-in-use (Payne and Frow, 2017). Therefore, SVAs develop close communication processes with users, oriented to the generation of user retention, loyalty and long-term profitability (Gwinner et al., 1998; Palmer and Bejou, 1994; Wuenderlich et al., 2015).

The aim of the present paper is to study the affective nature of relationships that users may establish with SVAs (e.g. Siri, Alexa or Cortana, for example) during their interactions. For that, the paper examines, first, what factors lead users to perceive relational cohesion with their SVA and, second, how this cohesion promotes user engagement behaviors toward the brand of the SVA (e.g. Apple, Amazon, Google, Microsoft, etc.). We draw on the relational cohesion theory (RCT) (Lawler and Yoon, 1996) and propose that the interaction frequency between users and SVAs generates users' positive emotions, that is, pleasured-satisfaction and interest, these emotions eliciting relational cohesion. Moreover, we explore if this relational cohesion between users and SVAs goes beyond the technology and triggers relational ties with the brand of the SVA, concretely, user engagement. Engaged users consider that the brand is responsible for the benefits that the SVA provides, so they seek to continue their relationships.
In summary, the current paper intends to answer the following research questions: What are the key drivers that determine relational cohesion between users and SVAs? What is the nature of the relationship between users and SVAs? And how does the relational cohesion between users and SVAs (e.g. Siri, Alexa or Cortana) condition user engagement behaviors toward the brand of the SVA (e.g. Apple, Amazon or Microsoft)?

The contributions of this study are threefold. First, this is one of the first manuscripts that explore relationship marketing between users and SVAs, focusing on interaction frequency, emotions and relational constructs, instead of emphasizing technological capabilities and cognitive criteria. So, this paper breaks with previous research on information technologies and defines foundations to explore smart technologies (De Keyser et al., 2019). Second, this paper brings a new scope of application for the RCT, exclusively used in interpersonal contexts, and demonstrates its adequacy to examine affective relationships with SVAs. Thereby, it offers a pioneering study that validates this conceptual framework in a technological context, responding to prior calls concerning the need for empirical research on conversational agents (Fernandes and Oliveira, 2021). Finally, this paper reveals that relational cohesion between users and SVAs acts as a psychological mechanism that not only determines the future use of the technology (consequences in the product-level) but also provokes user engagement behaviors toward the brand of the SVA (consequences in the brand-level). In this way, if the user establishes a cohesive relationship with Siri, for example, will (s)he will develop engagement with Apple, showing intentions to buy other products of Apple, recommending it to his/her his friends and providing it with suggestions to improve the service.

The paper is structured as follows. The next section develops the background to the study, reviews prior research on SVAs and critically evaluates it. Following this, the hypotheses are developed and the theoretical model proposed. Thereafter, the methodology and analyzes are presented and the findings discussed. In the final section, the theoretical contributions and managerial implications based on these findings are discussed, concluding with limitations and future research directions.

\section{Background}

SVAs are defined as disembodied conversational agents that differ from previous technologies based on screens (visual and tactile) because they use voice-based interfaces to communicate with users (audial) (Biele et al., 2019; Pagani et al., 2019). SVAs have the capacity of processing users' natural language, engaging users in human-like conversations that introduce new-found intimacy based on emotions and feelings, such as happiness, excitement and cohesion (Belk, 2017; Feng et al., 2017; Hoffman and Novak, 2018). So, SVAs infuse experiential service encounters that lead users to build interpersonal relationships with the technology, despite they know that are relating to a non-human (Han and Yang, 2018; De Keyser et al., 2019; Xu, 2020).

SVA employment has increased significantly during the past years, being expected that in 2021 it reaches a "critical mass" (eMarketer, 2021). Recent reports have shown that there are today 3,25,000 million SVAs worldwide and the estimate is 
that there will be over 8,000 million users by 2023 (Canalys, 2019). In fact, voice shopping sales are expected to increase, just in the USA and UK, from US $\$ 2$ bn in 2018 to an estimated US $\$ 40$ bn-plus in 2022. Thus, SVAs are expected to give rise to new service and engagement platforms that can provide firms with unprecedented opportunities (Capgemini Research Institute, 2019).

Existing research into SVAs can be placed on the following two main categories: studies that apply a technology-based approach and studies that apply a user-based approach.

Research on the first category examines what technological attributes of SVAs optimize their employment, focusing on aspects such as voice, language, security and privacy (de Barcelos Silva et al., 2020; Davenport et al., 2020; Poushneh, 2021). In traditional communication, the speaker's voice and language provide important information about her/him, such as emotions, credibility, reliability and personality factors (Nass et al., 1997; Till and Busler, 1998). Thereby, some studies establish that developing a unique pleasant voice for SVAs is crucial for them to be considered desirable social partners (Schuetzler et al., 2018). On the other hand, the issues of security and privacy have been indicated as big challenges that voice assistant applications need to deal with (de Barcelos Silva et al., 2020; Pal et al., 2020). In this line, some studies identify the security flaws present in SVAs, proposing also measures to counteract them (Pal et al., 2020).

The second (more developed) category of research analyzes how and why users employ SVAs, paying special attention to their perceptions, motivations, gratifications and behavioral intentions (McLean and Osei-Frimpong, 2019; Shin and Park, 2017). This research applies classic theoretical frameworks such as the technology acceptance model (Kowalczuk, 2018; Moriuchi, 2019; Sohn and Kwon, 2020), the uses and gratifications theory (McLean and Osei-Frimpong, 2019), the expectation confirmation theory (Brill et al., 2019) and the unified theory of acceptance and use of technology (Moriuchi, 2020). Findings demonstrate that perceptions such as ease of use and usefulness enhance user engagement and loyalty (Moriuchi, 2019), whereas perceived confirmation of expectations enhances user satisfaction with SVAs (Brill et al., 2019). Appendix 1 shows a compendium of the main publications on SVAs.

Despite the advances in knowledge that research on SVAs has achieved, there are still several gaps that should be addressed. First, previous studies are largely conceptual and apply theories that were elaborated to examine technologies lacking artificial intelligence (Lu et al., 2020). Nevertheless, the emergence of smart technologies leads to a new reality. These technologies are capable of learning users' likes and favorite topics, requiring little effort and no need to type, read or hold a device (Fernandes and Oliveira, 2021). So, they have caused a disruption in the study of human-technology interactions that opens new lines of research near to socio-psychological theories.

Second, it is highlighted that studies on SVA apply one-sided approaches that focus their attention on the technology or on the user but do not explore relationships that emerge between the two parties. In fact, these studies do not address the role of users' emotions, assuming that they make their decisions applying eminently cognitive criteria. Nevertheless, when users interact with smart technologies they feel that are involved in affective relationships with the service (Feine et al., 2019; Liao et al., 2019). So, they can develop feelings that to date have been considered only in interpersonal contexts, such as satisfaction, attachment and passion and establish long-term affiliations that go beyond human-computer interactions (Nass et al., 1994; Xu, 2020). New studies should empirically examine these relationships, focusing on concepts as user's emotions and affections that to date have hardly been treated.

Third, most studies examine consequences of user-SVA relationships-related exclusively to the use of the SVA, ignoring other fundamental relational ties in service marketing research such as user loyalty, engagement and trust. In fact, as far as we know, very few publications have gone one step further from the technology and have tested consequences related to the brand of the SVA (see, as exceptions, McLean et al., 2021; Pagani et al., 2019; Poushneh, 2021).

The present paper tries to fill these gaps, adding significant contributions to the body of knowledge. It evaluates the importance of affective relationships that users can establish with SVAs. Specifically, it empirically studies a model based on RCT (Lawler and Yoon, 1996), initially proposed to explore interpersonal relationships and demonstrates that relational cohesion can also study users' interactions with smart technologies. This cohesion channels the effect of positive emotions that users feel when they frequently interact with the SVA, leading them to develop engagement behaviors toward the brand of the SVA. Engaged users feel gratitude to the brand so they seek to maintain the relationship with the aim of receiving benefits again.

\section{Theoretical framework and hypotheses}

RCT is a tested framework that explains the process that determines individual commitment behaviors in a particular interpersonal relationship (Lawler and Thye, 1999; Lawler and Yoon, 1996; Thye et al., 2002). It stipulates that frequent exchanges between actors can elicit positive emotions (pleasure-based satisfaction and interest) which, in turn, generate subjective perceptions of unifying, cohesive relations (Lawler and Yoon, 1996; Michael and Pacherie, 2015). Relational cohesion is defined as the individual's perception that (s)he is part of a group, this relationship being a unifying element in the social situation (Lawler and Yoon, 1996). So, when individuals perceive relational cohesion, they exchange their doubts with the other party, search for suggestions about topics, tend to collaborate and seek to carry out new joint activities. These interpersonal activities lead individuals to feel interdependence and to develop observable acts of commitment (Parks and Floyd, 1996). Thus, RCT proposes a sequence of from-exchange-to-emotion-to-cohesion that encapsulates the psychological mechanism that influences individuals' behavioral outcomes, that is, the tendency for actors to stay in the exchange relation, to contribute to new joint ventures and to exchange token gifts (Lawler and Yoon, 1996; Salmela and Nagatsu, 2017; Zheng, 2020).

RCT has been only applied to study interpersonal relationships in different contexts. For example, Yoon and Lawler (2006) studies the relational cohesion model to analyze organizational commitment while Huang et al. (2018) theorizes the process by 
which online relationships are formed between users of social networks. Nevertheless, to the authors' knowledge there is not yet any existing work testing the cohesive relationship that emerges between users and technologies after making frequent and successful interactions. In this way, we adapt RCT to study affective relationships between users and SVAs, considering an endogenous process formed by two phases. First, we examine interaction frequency and positive emotions (i.e. pleasure-based satisfaction and interest) that determine users' relational cohesion with their SVA. Second, we explore the impact of relational cohesion on user engagement behaviors toward the brand of the SVA: continuing purchasing other products of the brand, providing knowledge to the brand and referring the brand.

Figure 1 shows a summary of the proposed model.

\section{Users' relational cohesion with their smart voice} assistant: interaction frequency and positive emotions The endogenous process proposed in RCT establishes that exchange frequency is the starting point of cohesion in a relationship. Exchanges refer to the process through which two or more parties in a relationship collaborate and make joint efforts to complete tasks and share mutual benefits (Lawler et al., 2000). If these exchanges are successful, they provide positive feedback and encourage parties to repeat behavior, which may generate further positive feedback. In other words, attaining success in an exchange boosts parties to engage in new exchanges, promoting the frequency of positive experiences and making them feel happy and satisfied (Lizardo, 2007). Moreover, successful exchanges generate trust among parties, which motivates them to be cooperative and to search together for new achievements (Lawler et al., 2000). In this way, the relationship that parties establish provokes positive emotions, such as pleasure-satisfaction and interest (Lawler et al., 2000).

Pleasure-based satisfaction is defined as a backward-looking emotion that occurs after something is gained (Lawler and Yoon, 1993, 1996). It is based on real judgments derived from experiences and involves a greater degree of stability than assessments based on attitudes (Bhattacherjee, 2001). On the other hand, interest is defined as the feeling of eager to do and enjoy an activity or subject (Lawler et al., 2000). It is a forwardlooking emotion based on the awareness of potential satisfaction in anticipation of possible gains (Lawler and Yoon, 1993, 1996, 2006).

Figure 1 Proposed model

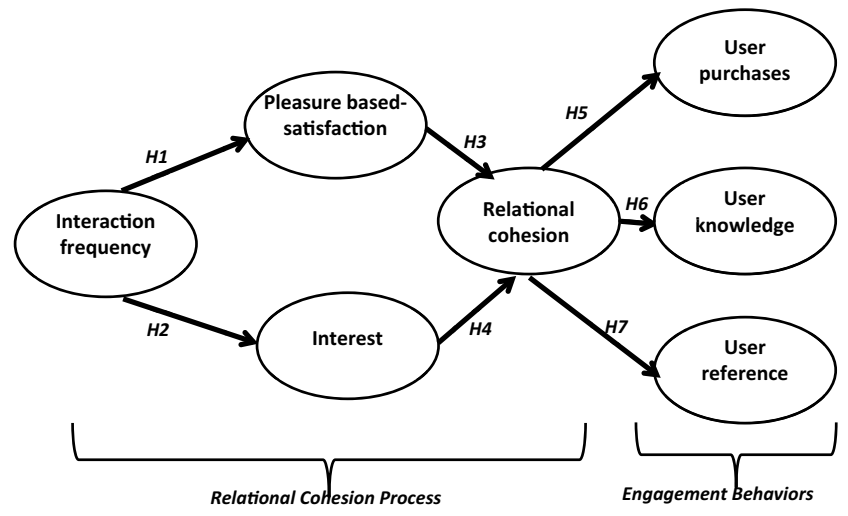

Based on these arguments, we define exchange frequency in the SVA context as the frequency of interactions that the user carries out to accomplish her/his objectives and to obtain benefits provided by the technology. Frequent and successful interactions reduce uncertainties in the relation and increase the user's knowledge about the technology, also boosting the SVA cognition. This cognition generates a greater personalization of the relationship and improves the quality of the service. Thereby, frequent and successful user-SVA interactions provide users with enriching experiences and evoke positive emotions, specifically pleasure-based satisfaction with and interest in this technology:

H1. Frequent users' interactions with SVAs improve their pleasure-based satisfaction.

H2. Frequent users' interactions with SVAs improve their interest.

Pleasure-based satisfaction refers to the strong feeling of happiness and enjoyment that users may experience after interacting with SVAs (Lawler et al., 2000). So, if the performance of SVAs confirms users' expectations, they will be satisfied and will want to continue with the relationship. Satisfied users tend to be friendly and cooperative, share their personal information, and want to learn more about SVAs, trying to maximize benefits derived from using them. Therefore, users' pleasure-based satisfaction forms an emotional attachment with SVAs that leads them to build close relationships with the technology and to feel relational cohesion (Huang et al., 2018; Kim and Gweon, 2016):

H3. Users' pleasure-based satisfaction emotions positively influence their relational cohesion with SVAs.

Interest refers to the enthusiasm and excitement that users feel about their interactions with SVAs. So, when users are interested in SVAs, they want to spend and enjoy their time with them (Lawler et al., 2000). These feelings make users to experience enhanced engagement in joint tasks, which promotes repeated and successful interactions (Huang et al., 2018). As a result, users become more attached to and integrated in the relationships with, their SVA, which is essential for the development of relational cohesion:

H4. Users' interest emotions positively influence their relational cohesion with SVAs.

\section{Users' relational cohesion with their smart voice assistant and engagement behaviors with the brand of the assistant}

Customer engagement is defined as the customers' behavioral manifestations toward a brand or firm, resulting from motivational drivers (Van Doorn et al., 2010). It encompasses a wide range of behaviors toward a firm, such as word-of-mouth (WOM) activity, recommendations, helping other customers, blogging, writing reviews and even co-creation, which involves making suggestions to improve consumption experiences and coaching brands (Van Doorn et al., 2010). Customer engagement is close to other classic concepts, such as satisfaction, attachment and loyalty, but it differs from them in that it has a behavioral focus, being one of their main 
consequences. In other words, high levels of satisfaction, attachment and loyalty lead to high customer engagement (Anderson and Mittal, 2000; Schau et al., 2009). An exhaustive review of the literature has shown that, although the definition and components of customer engagement can vary, most authors agree on the various ways that engaged customers contribute to firms (Kumar and Pansari, 2016).

For the purpose of this study, we propose that the effect of the relational cohesion perceived by users with their SVA influences user engagement with the brand of the SVA (Hatfield et al., 2008). This perception implies users' feelings of interdependence and gratitude, generating behavioral intentions to maintain the relation with the brand because they consider that it is the source of their positive emotions. So, going beyond consequences related to the technology (productlevel), we propose that users' relational cohesion with their SVA is reflected on their engagement with the brand of the assistant (brand-level). We follow the conceptualization of engagement of Kumar et al. (2010) because it is comprehensive and considers different behavioral consequences: continuing purchasing other products of the brand, providing knowledge to the brand and referring the brand.

The users' relationship with their SVA provides them with benefits that they want to continue to maintain, considering that the money they spent on the smart service is well spent. Users are happy with the SVA, so they decide to continue to patronize the SVA brand, and express their intentions to continue buying other additional products, despite the availability of attractive alternatives offered by other brands. In this context, users' purchases relate not only to the simple undertaking of future transactions but also their desire to share a long-term relationship with the SVA brand. Consequently, they directly contribute to company value and produce increments in revenue without any increase in the firm's marketing investment:

H5. Users' relational cohesion with SVAs positively influences their intentions to continue purchasing other products of the SVA brand.

Relational cohesion also generates cooperative interaction between the parties. They work together to pursue a common purpose and, consequently, share the success achieved (Hauert et al., 2007). When users perceive that they are in a cohesive relationship with their SVA, they exchange and share information by using a specific dialogue, thus improving mutual understanding (Parks and Floyd, 1996). Moreover, users' perceptions of cohesion with their SVA make them feel that they belong to a brand community that supports the service. Consequently, they get involved and actively collaborate to improve the brand's performance by providing suggestions and feedback about their experiences and interactions with their SVA (Kumar and Pansari, 2016; Lawler and Yoon, 1996). Users, thus add value by helping the SVA brand understand their preferences and by participating in the knowledge development process (Joshi and Sharma, 2004). SVA brand can use this knowledge to improve and/or create new smart services compatible with its SVA, providing additional value to the user (Kumar and Bhagwat, 2010):
H6. Users' relational cohesion with SVAs positively influences their intentions to contribute knowledge to the SVA brand.

Finally, relational cohesion involves the parties in a relationship where token gifts are exchanged (Lawler and Yoon, 1996). In the user-SVA relationship, we link these gifts with the role that users play when they refer the SVA brand. Users that refer the brand may not make the most purchases, but they are more profitable than other, similarly-profiled users (Schmitt et al., 2011). In this way, when users perceive relational cohesion with their SVA, they make positive referrals of the SVA brand and help it to reach other users who would not be attracted by traditional marketing channels, thus contributing to overall user engagement (Kumar et al., 2010):

H7. Users' relational cohesion with SVAs positively influences their intentions to make referrals of the SVA brand.

\section{Methodology}

\section{Sample}

The target population of this study is formed by regular SVA users, who know this smart technology and make frequent and diverse employments. To obtain a representative sample of this population, researchers hired an international market research company, specialized in studies about online customer behavior, electronic commerce and acceptance of new technologies, etc. This company works with several consumer panels and establishes long-term relationships with members. To be a member of one of these panels, consumers should answer surveys that address topics such as housing, banking and telecommunications. In this way, the company classifies consumers according to their habits, uses and consumptions, identifying different profiles. All panels are certified with ISO 26362.

The market research company designed an online platform specifically for this project and elaborated email invitations to participate. These invitations were exclusively sent to a panel of US users of telecommunications, with more than 6,900 members (3,286 women), who had stated that they knew and used SVAs. Invitations included a one-time personal link, which prevented self-selection bias and duplications. Moreover, panel members did not know the aim of the study. The data were collected in November 2018.

To guarantee that participants were effectively regular users of SVAs, they had to answer a first filter question as follows: Do you regularly use a SVA? Only those participants who answered "yes" could continue answering the survey. Afterward, they had to answer other questions related to SVA characteristics, types of services, brands and devices. Participants that answered these questions incorrectly, raising doubts about their real experience with SVAs, were removed from the study. All these questions guaranteed that participants were regular users and ensured the reliability of the responses. Finally, a total of 717 valid responses were obtained. Of the respondents, $78.9 \%$ were men, $40.2 \%$ were between 25 and 37 years of age, and $38.7 \%$ between 38 and 54 years of age. Regarding the 
Blanca Hernández-Ortega, Joaquin Aldas-Manzano and Ivani Ferreira

education level, $58.8 \%$ had at least a university degree. Respondents interact with their SVA at least $10 \mathrm{~h}$ in a week.

\begin{abstract}
Measures
The information was obtained through a survey with closed questions. The research constructs were operationalized using items adopted from previous research (Table 1). The variables were measured using seven-point Likert-type scales, where 1 indicated complete disagreement with the statement and 7 complete agreement. First, the survey included general questions about SVAs, the participant's experience as a user, frequency interactions, types of uses (s)he makes and the brand that supports her/his SVA. Second, the survey asked about emotions that the participant feels during her/his interactions with the SVA and about the characteristics of their relationship. Then, the survey recalled the main existing SVA brands (e.g. Amazon, Apple, Google, Microsoft, Samsung, etc.) and asked the participant to mentally identify the brand of her/his SVA. Finally, the survey included questions related to user engagement with the brand of the SVA.

Pre-tests of the questionnaire were carried out to correct possible defects and to identify doubts and problems that might arise during the information-gathering process. First, 10 marketing and Business Management Professors were asked to assess the conceptual adequacy and formulation of the questions. Second, the survey was administered to 20 regular SVA users. These respondents had similar characteristics to the target population that was to be examined. Pre-tests requested the respondents to complete the questionnaire and provide feedback. As a result of the pre-tests some redundant questions were eliminated and some of the scales were adapted to facilitate understanding and to avoid erroneous interpretations.
\end{abstract}

\section{Check of common method variance}

The data were obtained through a single collection method, therefore, to prevent common method bias we followed Podsakoff et al. (2003)'s and MacKenzie and Podsakoff (2012)'s recommendations.

First, during data collection, the anonymity of participants' responses was guaranteed and the exact aim of the study was not disclosed, avoiding conditioning participants' responses.

Second, items related to the dependent variables were placed in the questionnaire after items that measured independent variables. In addition, the participants' access to their responses to previous questions was limited so that their subsequent responses were not determined by their previous answers.

Third, the absence of common method bias in the data was statistically checked using Harman's single factor test using confirmatory factor analysis (CFA) as suggested by Malhotra et al. (2006), where all the manifest items are modeled as the indicators of a single factor that represent the method effect. The poor fit of the model [Satorra-Bentler (SB) $-\chi^{2}(324)=$ 4,433.4; comparative fit index $(\mathrm{CFI})=0.680$; Tucker-Lewis index $(\mathrm{TLI})=0.654$; root mean square of error approximation $(\mathrm{RMSEA})[90 \% \mathrm{CI}]=0.133[0.130 ; 0.136]]$ revealed no substantial method bias. Fourth, the single common method approach proposed by Podsakoff et al. (2003) ${ }^{[1} 1^{[}$was implemented as Williams et al. (1989) and Facteau et al. (1995) suggested. We estimated, first, the 8 traits measurement model and, second, the 8 traits measurement model plus a single uncorrelated method factor. Although the second model fitted significantly better $\left(\mathrm{SB}-\chi^{2}(276)=575.47\right.$; CFI $=0.977$; TLI $=0.971 ;$ RMSEA $[90 \% \mathrm{CI}]=0.048[0.042 ; 0.053])$, the variance accounted for the method factor was $12 \%$, significantly lower than the $27 \%$ reported by Williams et al. (1989). So, it is reasonable to conclude that common method bias was not a serious problem in this study (Choi and Chen, 2007; Facteau et al., 1995).

\section{Analyzes and results}

Covariance-based structural equation modeling (CB-SEM) analysis was developed in two steps. First, the measurement model was estimated through CFA to test the psychometric properties of the scales (i.e. reliability and validity). Second, the structural model was estimated to test the hypotheses (EQS 6.1 software).

\section{Confirmatory factor analysis}

The results obtained in the estimation confirmed the goodness of fit of the factorial structure to the empirical data. The following three types of fit criteria most widely used in the structural equation modeling (SEM) literature were applied (Hair et al., 2010): the measure of absolute fit, the measure of incremental fit and the measure of parsimonious fit. The results, summarized in Appendix 2, confirmed that the BentlerBonnet normed fit index (BBNFI), TLI, incremental fit index (IFI) and CFI statistics exceeded the optimal levels of 0.9 . The RMSEA was lower than 0.08 and the normed $\chi^{2}$ had a value lower than the recommended 5.0.

The reliability of the scales was tested using the composite reliability coefficient and average variance extracted (AVE). In all cases, the results exceeded the recommended limits of 0.7 (Bagozzi and Yi, 1988) and 0.5 (Fornell and Larcker, 1981), respectively. Therefore, the indicators showed high internal consistency.

As evidence of convergent validity, the results showed that all indicators were significant $(p<0.01)$, had an explanatory coefficient $\left(R^{2}\right)$ higher than 0.50 (Jöreskog and Sörbom, 1993) and their standardized factor loadings were higher than 0.70 (Bagozzi and Yi, 1988).

The discriminant validity of the measures was evaluated by calculating the $99 \%$ confidence interval of the latent factor correlation matrix and verifying that 1.0 was not included in any of them (Anderson and Gerbing, 1988). Moreover, the square root of each construct AVE was higher than the correlation among factors, thus fulfilling the criterion established by Fornell and Larcker (1981). Hetero trait mono trait ratios (Henseler et al., 2009) were also lower than the conservative 0.85 benchmark (Hair et al., 2017) (Appendix 2).

The analyzes allowed us to conclude that the measurement scales met the psychometric properties required in the literature and were, therefore, appropriate.

\section{Structural model analysis}

Thereafter, the proposed causal model was tested. The results indicated that the data were in accordance with the proposed conceptual model: $\mathrm{RMSEA}=0.070 ; \mathrm{TLI}=0.894 ; \mathrm{YLI}=0.905$; $\mathrm{CFI}=0.915 ; \mathrm{IFI}=0.915$. The effect size in CB-SEM is given by 
Blanca Hernández-Ortega, Foaquin Aldas-Manzano and Ivani Ferreira

Table 1 Measurement scales

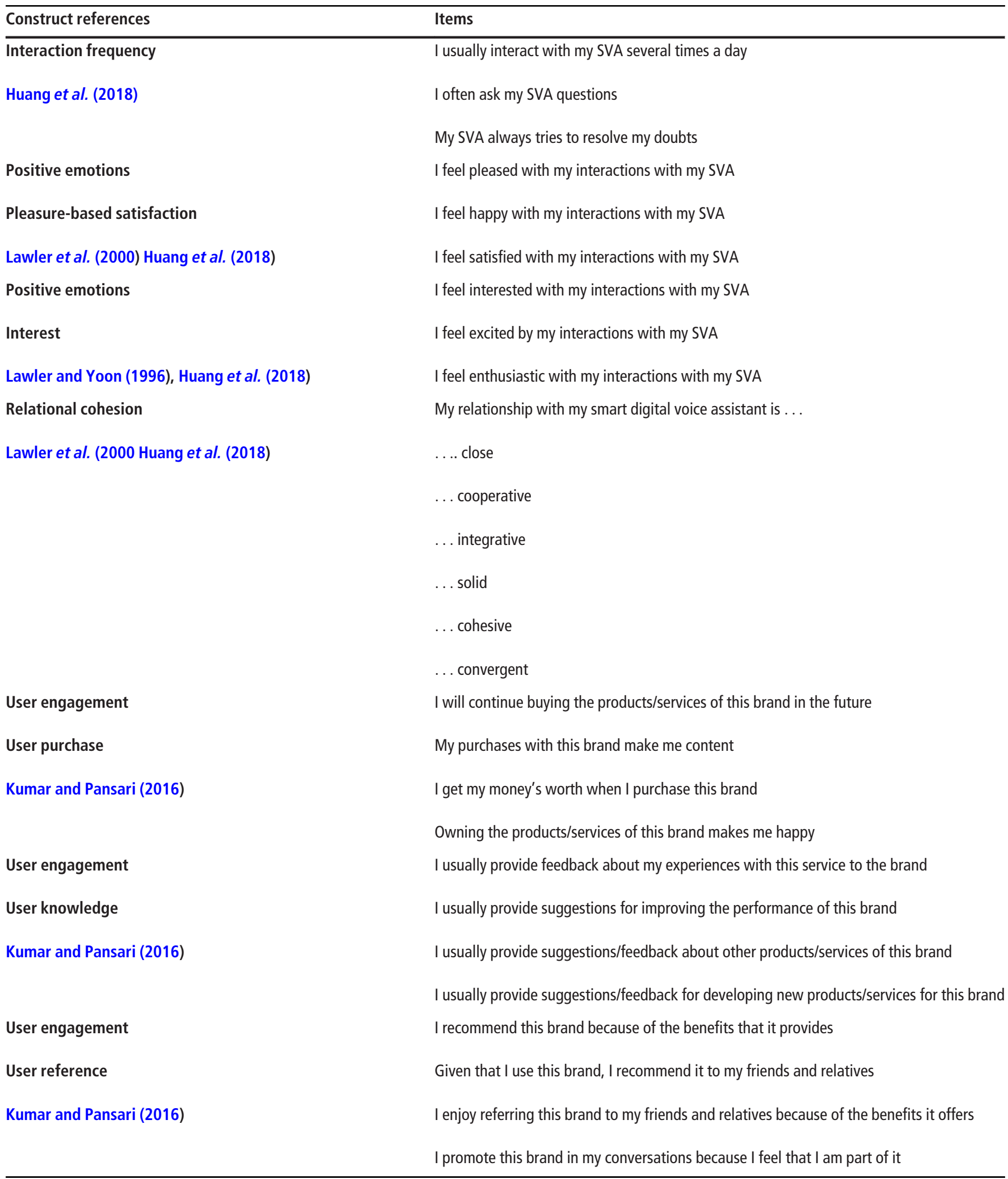


testing the maximum likelihood hypothesis, that is, the chisquare $\left(\chi^{2}\right)$ statistic: SB- $\chi^{2}=1,404.069$, d.f. $=313, p=0.000$.

The results show that interaction frequency positively influences users' emotions, improving pleasure-based satisfaction $\left(H 1: \beta_{1}=0.729 ; p<0.01\right)$ and interest $\left(H 2: \beta_{2}=\right.$ $0.631 ; p<0.01)$ with SVAs. These emotions enhance relational cohesion with the SVA $\left(H 3: \beta_{3}=0.535 ; p<0.01\right.$ for satisfaction, and H4: $\beta_{4}=0.497 ; p<0.01$ for interest), obtaining a joint explanatory power of 0.798 . Finally, relational cohesion determines user engagement behaviors toward the brand of the SVA, that is, user purchases (H5: $\beta_{5}=0.713$; $p<$ $0.01)$, user knowledge (H6: $\left.\beta_{6}=0.727 ; p<0.01\right)$ and user reference $\left(H 7: \beta_{7}=0.748 ; p<0.01\right)$ (Table 2$)$.

The model achieves explanatory powers of $0.508,0.529$ and 0.560, for user purchases, user knowledge and user reference, respectively. These values demonstrate the importance of obtaining relational cohesion between users and their SVA to promote their engagement behaviors toward the brand of the SVA.

\section{Discussion}

The findings verify the adequacy of RCT to explore relationships between users and SVAs. They show that frequent interactions and positive emotions (pleasure-based satisfaction and interest) turn users-SVAs exchanges into affective relationships, similar to those established between humans. Thus, the more frequent the interactions are, the more positive users' emotions are and the more cohesion they feel with the assistant.

Moreover, relational cohesion has a positive impact on the brand of the SVA. Thereby, the findings demonstrate that cohesion perceived by the user with the SVA not only conditions the future relationship with the technology but also generates user engagement behaviors toward the brand. The effect of relational cohesion on user reference of the brand is the most important, followed by user knowledge and future purchases that the user intends to make of other products of that brand. Therefore, the findings reveal that users with close relationships with their SVA generate direct value to the brand of the SVA, referring it to other users, contributing with feedback and making new purchases.

\section{Conclusions}

\section{Theoretical contributions}

The present study makes three important contributions to the existing literature.
First, this is one of the first studies that examines relationship marketing between users and SVAs. It goes beyond the technological approach predominantly applied in research on smart technologies (Davenport et al., 2020; Pagani et al., 2019; Poushneh, 2021), and focuses its attention on user interactions, emotions and relational constructs. Our findings show that future studies should address not only users' perceptions about SVAs (Kowalczuk, 2018; Moriuchi, 2019; Yang and Lee, 2019) but also the nature of the relationships between them. They demonstrate that frequent interactions boost cohesive relationships, based on principles such as cooperation, collaboration and integration. Therefore, this paper breaks with previous studies on information technologies and opens new lines to explore smart technologies. These findings are consistent with research on relationship marketing in services, which demonstrates that the frequency of service encounters has a positive impact on the strength of relationships between providers and customers (Barnes, 1997; Berry, 1995; Ward and Dagger, 2007).

Second, this paper demonstrates the adequacy of RCT to examine smart technologies, despite this theory had been exclusively applied to explore relationships between humans (Lawler and Thye, 1999; Lawler and Yoon, 1996; Thye et al., 2002). This paper considers that special characteristics of smart technologies turn them into main actors and make users behave differently than with previous technologies. So, findings demonstrate that users feel satisfaction with and interest in SVAs just as they feel these positive emotions toward other people. In this way, the present study responds to prior calls for empirical research on conversational agents (De Keyser et al., 2019; Fernandes and Oliveira, 2021). According to these findings, future research should examine conceptual models based on socio-psychological theories with the aim of capturing the relevance of subjective factors inherent to individuals.

Third, this study sheds conceptual light on the process that drives the user to develop engagement behaviors toward the brand of the SVA, establishing relational cohesion as an essential mechanism that channels the effect of antecedents. Previous studies have mostly examined outcomes of users' employment in the product-level such as future use of the technology (Fernandes and Oliveira, 2021; Pridmore and Mols, 2020), without taking into account that interactions can also generate consequences in the brand-level. Our findings show that relational cohesion leads successful interactions and positive emotions to improve the user engagement behaviors with the brand of the SVA. These findings are consistent with research on engagement conducted by Kumar et al. (2010) and

Table 2 Results

\begin{tabular}{|c|c|c|c|c|}
\hline Hypothesis & Relationship & Standardized coefficient & $t$-value (robust) & Results \\
\hline$\overline{H 1}$ & $\mathrm{FREQ} \rightarrow \mathrm{SAT}$ & $0.729^{* * *}$ & 13.95 & $\overline{\text { Supported }}$ \\
\hline$H 2$ & FREQ $\rightarrow$ INT & $0.631^{* * *}$ & 13.79 & Supported \\
\hline H3 & $\mathrm{SAT} \rightarrow \mathrm{RECH}$ & $0.535^{* * *}$ & 15.22 & Supported \\
\hline H4 & $\mathrm{INT} \rightarrow \mathrm{RECH}$ & $0.497^{* * *}$ & 12.76 & Supported \\
\hline H5 & $\mathrm{RECH} \rightarrow \mathrm{PUR}$ & $0.713^{* * *}$ & 15.10 & Supported \\
\hline$H 6$ & $\mathrm{RECH} \rightarrow \mathrm{KNO}$ & $0.727^{* * *}$ & 20.36 & Supported \\
\hline$H 7$ & $\mathrm{RECH} \rightarrow \mathrm{REF}$ & $0.748^{* * *}$ & 16.61 & Supported \\
\hline
\end{tabular}


Blanca Hernández-Ortega, Joaquin Aldas-Manzano and Ivani Ferreira

Kumar and Pansari (2016) and demonstrate that cohesive relationships between users and SVAs do not only influence their private union but also incentivize referral of new users.

\section{Managerial implications}

Our findings provide specific, actionable insights for managers.

\section{Managers should encourage as many user-smart voice assistant interactions as possible}

According to our findings, interaction frequency is a key trigger for users to develop engagement with the brand of the SVA. For this reason, we recommend firms to gradually conquer different areas of user daily lives, advancing slowly and safely. First, they should start transmitting the benefits that users can obtain from the employment of SVAs to perform easy tasks. Then, once users have acquired knowledge and familiarity, firms should promote the application of SVAs to carry out more complex activities. So, the more frequent interactions between SVAs and users are, the stronger their relationship.

Managers should implement relational strategies oriented to generate cohesion between users and smart voice assistants

These strategies can channel the effects of users' interactions with their SVA and foster the establishment of affective relationships based on cohesion. In this way, users might perceive that their relationships with their SVA are genuine and different to their relationships with other technologies, due to the human-like conversations, based on machine learning, that they hold with them. Machine learning allows SVAs to understand users' likes, to anticipate their needs and to offer personalized solutions. These aspects can foster users' feelings toward their SVA, minimize pain points and lead to engagement. Accordingly, the challenge for managers is to design smart services that take the initiative, provide unique experiences, and empower users by allowing them to define the kind of exchanges that they want to experience.

Managers should boost user-smart voice assistant cohesion with the aim of obtaining value through user engagement with the brand of the assistant

Findings demonstrate that users' cohesive relationships with SVAs make them to be engaged with the brand of the SVA. So, users create value for the firm by making new purchases and by developing non-financial behaviors. First, engaged users consider that the brand is responsible for the benefits that SVAs provide, so they seek to consume other products from the brand to continue receiving similar benefits. Second, engaged users provide feedback to the firm with ideas for improvements and new services. This feedback is derived from user personnel experiences with SVAs, is given constructively, and allows the firm to obtain knowledge from the direct consumption of its services. Third, engaged users exhibit referral and WOM behaviors, which generate and disseminate information that affects other users' purchase perceptions and decisions. In this way, engaged users increase companies' reputations and contribute to brand recognition. In general, relational cohesion provokes user engagement behaviors that promote the establishment of close relationships with current and potential users.

\section{Limitations and future research lines}

Although the findings of this study provide meaningful insights into the relationship between users, SVAs and brands of SVAs, several limitations should be taken into account for future research.

This study explores users' relational cohesion with their SVA and their engagement with the brand, but it did not differentiate between types of the assistant. Future research might compare interaction frequency, user emotions and relational cohesion with smartphone-based SVAs, such as Siri and Google Assistant, and these same variables with in-home voice assistants, such as Amazon Echo and Google Home. User-SVA interactions in each case, and the kinds of relationship that are established, can vary, which might generate different levels of user engagement with the brand of the SVA. Future research should also address users' perceptions and behavioral intentions toward brands using SVAs to assist them in routine shopping.

Moreover, the data were collected from regular SVA users in the USA. Further research might test the proposed model in different countries to assess the influence of culture on user behavior. It would be interesting to compare user-SVA relationships in countries with different levels of expertise. Finally, future studies should undertake longitudinal analyzes to test the evolution of relational cohesion between users and SVAs. Future studies should examine how positive emotions, relational cohesion and engagement change as the users employ the smart service over time, acquiring knowledge and skills.

\section{Note}

1. This method is recommended for situations in which predictor and criterion variables cannot be obtained from different sources and the sources of the method bias cannot be identified.

\section{References}

Anderson, J.C. and Gerbing, D.W. (1988), "Structural equation modeling in practice: a review and recommended two-step approach", Psychological Bulletin, Vol. 103 No. 3, pp. 411-423.

Anderson, E. and Mittal, V. (2000), "Strengthening the satisfaction-profit chain", fournal of Service Research, Vol. 3 No. 2, pp. 107-120.

Bagozzi, R.P. and Yi, Y. (1988), "On the evaluation of structural equation models", Fournal of the Academy of Marketing Science, Vol. 16 No. 1, pp. 74-94.

Barnes, J.G. (1997), "Exploring the importance of closeness in customer relationships", American Marketing Association, Vol. 6, pp. 227-240.

Belk, R. (2017), "The soul and the machine: Humanlike machines and machinelike humans", in Gneezy, A., Griskevicius, V. and Williams, P. (Eds), NA-Advances in Consumer Research, Vol. 45, Association for Consumer Research, Duluth, MN, pp. 164-169.

Berry, L.L. (1995), "Relationship marketing of servicesgrowing interest, emerging perspectives", fournal of the Academy of Marketing Science, Vol. 23 No. 4, pp. 236-245. 
Bhattacherjee, A. (2001), "Understanding information systems continuance: an expectation-confirmation model", MIS Quarterly, Vol. 25 No. 3, pp. 65-79.

Biele, C., Jaskulska, A., Kopec, W., Kowalski, J., Skorupska, K. and Zdrodowska, A. (2019), "How might voice assistants raise our children?", International Conference on Intelligent Human Systems Integration, Springer, pp. 162-167.

Brill, T.M., Muñoz, L. and Miller, R.J. (2019), "Siri, Alexa, and other digital assistants: a study of customer satisfaction with artificial intelligence applications", fournal of Marketing Management, Vol. 35 Nos 15/16, pp. 1401-1436.

Čaić, M., Mahr, D. and Odekerken-Schröder, G. (2019), "Value of social robots in services: social cognition perspective", fournal of Services Marketing, Vol. 33 No. 4, pp. 463-478.

Canalys (2019), "Rise of Alexa, Google assistant and Siri to drive US smart assistant-compatible device base to 1.6 billion in 2022", available at: www.canalys.com/newsroom/rise-of-alexagoogle-assistant-and-siri-to-drive-us-smart-assistant-compatibledevice-base-to-16-billion-in-2022 (accessed 01/25/21)

Capgemini Research Institute (2019), "Smart talk. How organizations and consumers are embracing voice and chat assistants”, available at: www.capgemini.com/wp-content/ uploads/2019/09/Report-\%E2\%80\%93-ConversationalInterfaces_Web-Final.pdf

Choi, J. and Chen, C.C. (2007), "The relationships of distributive justice and compensation fairness to employee attitudes in international joint ventures", fournal of Organizational Behavior, Vol. 28 No. 6, pp. 687-703.

Chouk, I. and Mani, Z. (2019), "Factors for and against resistance to smart services: role of consumer lifestyle and ecosystem related variables", fournal of Services Marketing, Vol. 33 No. 4, pp. 449-462.

Davenport, T., Guha, A., Grewal, D. and Bresgott, T. (2020), "How artificial intelligence will change the future of marketing", fournal of the Academy of Marketing Science, Vol. 48 No. 1, pp. 4-42.

de Barcelos Silva, A., Gomes, M.M., da Costa, C.A., da Rosa Righi, R., Barbosa, J.L.V., Pessin, G., De Doncker, G. and Federizzi, G. (2020), "Intelligent personal assistants: a systematic literature review", Expert Systems with Applications, Vol. 147, in press.

De Keyser, A., Köcher, S., Alkire, L., Verbeeck, C. and Kandampully, J. (2019), "Frontline service technology infusion: conceptual archetypes and future research directions", fournal of Service Management, Vol. 30 No. 1, pp. 156-183.

eMarketer (2021), "Voice assistant use reaches critical mass", available at: www.emarketer.com/content/voice-assistantuse-reaches-critical-mass (accessed 01/25/21)

Facteau, J.D., Dobbins, G.H., Russell, J.E.A., Ladd, R.T. and Kudisch, J.D. (1995), “The influence of general perceptions of the training environment on pretraining motivation and perceived training transfer", fournal of Management, Vol. 21 No. 1, pp. 1-25.

Feine, J., Gnewuch, U., Morana, S. and Maedche, A. (2019), "A taxonomy of social cues for conversational agents", International Fournal of Human-Computer Studies, Vol. 132, pp. 138-161.
Feng, H., Fawaz, K. and Shin, K.G. (2017), "Continuous authentication for voice assistants", Proceedings of the 23rd Annual International Conference on Mobile Computing and Networking, ACM, pp. 343-355.

Fernandes, T. and Oliveira, E. (2021), "Understanding consumers' acceptance of automated technologies in service encounters: drivers of digital voice assistants adoption", Fournal of Business Research, Vol. 122, pp. 180-191.

Fornell, C. and Larcker, D.F. (1981), "Structural equation models with unobservable variables and measurement error: algebra and statistics", fournal of Marketing Research, Vol. 18 No. 3, pp. 382-388.

Gummerus, J., von Koskull, C. and Kowalkowski, C. (2017), "Gest editorial: relationship marketing- past, present and future", fournal of Services Marketing, Vol. 31 No. 1, pp. 1-5.

Gwinner, K., Gremler, D. and Bitner, M.J. (1998), "Relational benefits in services industries: the customer's perspective", Fournal of the Academy of Marketing Science, Vol. 26 No. 2, pp. 101-114.

Hair, J., Black, W.C., Babin, B.J. and Anderson, R.E. (2010), Advanced Diagnostics for Multiple Regression: A Supplement to Multivariate Data Analysis, Pearson Prentice Hall Publishing.

Hair, J.F., Sarstedt, M., Ringle, C.M. and Gudergan, S.P. (2017), Advanced Issues in Partial Least Squares Structural Equation Modeling, Sage, London.

Han, S. and Yang, H. (2018), "Understanding adoption of intelligent personal assistants: a parasocial relationship perspective", Industrial Management \& Data Systems, Vol. 118 No. 3, pp. 618-636.

Hatfield, E.C., Pillemer, J.T., O'Brien, M. and Le, Y.C.L. (2008), "The endurance of love: passionate and companionate love in newlywed and long-term marriages", Interpersona: An International fournal on Personal Relationships, Vol. 2 No. 1, pp. 35-64.

Hauert, C., Traulsen, A., Brandt, H., Nowak, M.A. and Sigmund, K. (2007), "Via freedom to coercion: the emergence of costly punishment", Science, Vol. 316 No. 5833, pp. 1905-1907.

Henseler, J., Ringle, C. and Sinkovics, R. (2009), "The use of partial least squares path modeling in international marketing", Advances in International Marketing, Vol. 20, pp. 277-319.

Hoffman, D.L. and Novak, T.P. (2018), "Consumer and object experience in the internet of things: an assemblage theory approach", fournal of Consumer Research, Vol. 44 No. 6, pp. 1178-1204.

Hoy, M.B. (2018), "Alexa, Siri, Cortana, and more: an introduction to voice assistants", Medical Reference Services Quarterly, Vol. 37 No. 1, pp. 81-88.

Huang, H.C., Cheng, T.C.E., Huang, W.F. and Teng, C.I. (2018), "Who are likely to build string online social networks? The perspectives of relational cohesion theory and personality theory", Computers in Human Behavior, Vol. 82, pp. 111-123.

Huang, M.H. and Rust, R.T. (2018), “Artificial intelligence in service”, Fournal of Service Research, Vol. 21 No. 2, pp. 155-172.

Jöreskog, K. and Sörbom, D. (1993), LISREL 8 Structural Equation Modeling with the Simplis Comand Language, Scientific Software International, Chicago, IL. 
Joshi, A.W. and Sharma, S. (2004), "Customer knowledge development: antecedents and impact on new product performance", Fournal of Marketing, Vol. 68 No. 4, pp. 47-59.

Kabadayi, S., Ali, F., Choi, H., Joosten, H. and Lu, C. (2019), "Smart service experience in hospitality and tourism services. A conceptualization and future research agenda", fournal of Service Management, Vol. 30 No. 3, pp. 326-348.

Kim, A. and Gweon, G. (2016), "Comfortable with friends sharing your picture on Facebook? Effects of closeness and ownership on picture sharing preference", Computers in Human Behavior, Vol. 62, pp. 666-675.

Kowalczuk, P. (2018), "Consumer acceptance of smart speakers: a mixed methods approach", Fournal of Research in Interactive Marketing, Vol. 12 No. 4, pp. 418-431.

Kumar, V., Aksoy, L., Donkers, B., Venkatesan, R., Wiesel, T. and Tillmanns, S. (2010), "Undervalued or overvalued customers: capturing total customer engagement value", Fournal of Service Research, Vol. 13 No. 3, pp. 297-310.

Kumar, V. and Bhagwat, Y. (2010), "Listen to the customer", Marketing Research, Vol. 22 No. 2, pp. 14-19.

Kumar, V. and Pansari, A. (2016), "Competitive advantage through engagement”, fournal of Marketing Research, Vol. 53 No. 4, pp. 497-514.

Kunz, W., Heinonen, K. and Lemmink, J. (2019), "Future service technologies - is service research on track with business reality?", fournal of Services Marketing, Vol. 33 No. 4, pp. 479-487.

Lawler, E.J., Thye, S.R. and Yoon, J. (2000), "Emotion and group cohesion in productive exchange", American fournal of Sociology, Vol. 106 No. 3, pp. 616-657.

Lawler, E.J. and Yoon, J. (1993), "Power and the emergence of commitment behavior in negotiated exchange", American Sociological Review, Vol. 58 No. 4, pp. 465-481.

Lawler, E.J. and Yoon, J. (1996), "Commitment in exchange relations: test of a theory of relational cohesion", American Sociological Review, Vol. 61 No. 1, pp. 89-108.

Lawler, E.J. and Thye, S.R. (1999), "Bringing emotions into social exchange theory", [Electronic version], from Cornell University, ILR School site, available at: http:// digitalcommons.ilr.cornell.edu/articles/1221 (accessed 07/ $11 / 2020)$

Liao, Y., Vitak, J., Kumar, P., Zimmer, M. and Kritikos, K. (2019), "Understanding the role of privacy and trust in intelligent assistant adoption", 14th International Conference, iConference, Washington, DC, March 31-April 3, 2019, Proceedings.

Lizardo, O. (2007), "Relational cohesion theory", in Ritzer, G. (Ed.), Encyclopedia of Sociology, Blackwell, New York, NY, pp. 3845-3848.

Lopatovska, I., Rink, K., Knight, I., Raines, K., Cosenza, K., Williams, H., Sorsche, P., Hirsch, D., Li, Q. and Martinez, A. (2018), "Talk to me: exploring user interactions with the Amazon Alexa", fournal of Librarianship and Information Science, Vol. 51 No. 4, doi: 10.1177/0961000618759414.

Lu, V.N., Wirtz, J., Kunz, W.H., Paluch, S., Gruber, T., Martins, A. and Patterson, P.G. (2020), "Service robots, customers and service employees: what can we learn from the academic literature and where are the gaps?", fournal of Service Theory and Practice, Vol. 30 No. 3, pp. 361-391.
McLean, G., Osei-Frimpong, K. (2019), "Hey Alexa... examine the variables influencing the use of artificial intelligent in-home voice assistants", Computers in Human Behavior, Vol. 99, pp. 28-37.

McLean, G., Osei-Frimpong, K. and Brhorst, J. (2021), "Alexa, do voice assistants influence consumer brand engagement? - Examining the role of AI powered voice assistants in influencing consumer brand engagement", Fournal of Business Research, Vol. 124, pp. 312-328.

MacKenzie, S.B. and Podsakoff, P.M. (2012), "Common method bias in marketing: causes, mechanisms, and procedural remedies", fournal of Retailing, Vol. 88 No. 4, pp. 542-555.

Malhotra, N.K., Kim, S.S. and Patil, A. (2006), "Common method variance in is research: a comparison of alternative approaches and a reanalysis of past research", Management Science, Vol. 52 No. 12, pp. 1865-1883.

Michael, J. and Pacherie, E. (2015), “On commitments and other uncertainty reduction tools in joint action", fournal of Social Ontology, Vol. 1 No. 1, pp. 89-120.

Moriuchi, E. (2019), “Okay, Google!: an empirical study on voice assistants on consumer engagement and loyalty", Psychology \& Marketing, Vol. 36 No. 5, pp. 489-501.

Moriuchi, E. (2020), "An empirical study on anthropomorphism and engagement with disembodied AIs and consumers' re-use behavior", Psychology \& Marketing, Vol. 38 No. 1, pp. 21-42.

Nass, C., Moon, Y. and Green, N. (1997), “Are machines gender neutral? Gender-stereotypic responses to computers with voices", Fournal of Applied Social Psychology, Vol. 27 No. 10, pp. 864-876.

Nass, C., Steuer, J. and Tauber, E.R. (1994), "Computers are social actors", Proceedings of the SIGCHI Conference on Human Factors in Computing Systems, ACM, pp. 72-78.

Ostrom, A.L., Parasuraman, A., Bowen, D.E., Patricio, L. and Voss, C.A. (2015), "Service research priorities in a rapidly changing context”, fournal of Service Research, Vol. 18 No. 2, pp. 127-159.

Pagani, M., Racat, M. and Hofacker, C.F. (2019), “Adding voice to the omnichannel and how that affects brand trust", Fournal of Interactive Marketing, Vol. 48, pp. 89-105.

Pal, D., Arpnikanondt, C. and Abdur Razzaque, M. (2020), "Personal information disclosure via voice assistants: the personalization-privacy paradox", SN Computer Science, Vol. 1 No. 5, p. 280.

Palmer, A. and Bejou, D. (1994), "Buyer-seller relationships: a conceptual model and empirical investigation", fournal of Marketing Management, Vol. 10 No. 6, pp. 495-512.

Park, J.H., Lee, C., Yoo, C. and Nam, Y. (2016), “An analysis of the utilization of Facebook by local Korean governments for tourism development and the network of smart tourism ecosystem", International fournal of Information Management, Vol. 36 No. 6, pp. 1320-1327.

Parks, M.R. and Floyd, K. (1996), "Making friends in cyberspace”, Fournal of Communication, Vol. 46 No. 1, pp. 80-97.

Payne, A. and Frow, P. (2017), "Relationship marketing: looking backwards towards the future", fournal of Services Marketing, Vol. 31 No. 1, pp. 11-15. 
Podsakoff, P.M., MacKenzie, S.B., Lee, J.Y. and Podsakoff, N.P. (2003), "Common method biases in behavioral research: a critical review of the literature and recommended remedies", Fournal of Applied Psychology, Vol. 88 No. 5, pp. 879-903.

Poushneh, A. (2021), "Impact of auditory sense on trust and brand affect through auditory social interaction and control", Fournal of Retailing and Consumer Services, Vol. 58, in press.

Pridmore, J. and Mols, A. (2020), "Personal choices and situated data: privacy negotiations and the acceptance of household intelligent personal assistants", Big Data $\mathcal{E}$ Society, Vol. January-June, pp. 1-12.

Salmela, M. and Nagatsu, M. (2017), "How does it really feel to act together? Shared emotions and the phenomenology of we-agency", Phenomenology and the Cognitive Sciences, Vol. 16 No. 3, pp. 449-470.

Santos, J., Rodrigues, J.J., Silva, B.M., Casal, J., Saleem, K. and Denisov, V. (2016), "An IoT-based mobile gateway for intelligent personal assistants on mobile health environments", Fournal of Network and Computer Applications, Vol. 71, pp. 194-204.

Schau, H.J., Muniz, A. and Arnould, E. (2009), "How brand community practices create value", fournal of Marketing, Vol. 73 No. 5, pp. 30-51.

Schmitt, P., Skiera, B. and Van den Bulte, C. (2011), "Referral programs and customer value", fournal of Marketing, Vol. 75 No. 1, pp. 46-59.

Schuetzler, R.M., Giboney, J.S., Grimes, G.M. and Nunamaker, J.F. Jr. (2018), "The influence of conversational agent embodiment and conversational relevance on socially desirable responding", Decision Support Systems, Vol. 114, pp. 94-102.

Shin, D.H. and Park, Y.J. (2017), "Understanding the internet of things ecosystem: multi-level analysis of users, society, and ecology", Digital Policy, Regulation and Governance, Vol. 19 No. 1, pp. 77-100.

Sohn, K. and Kwon, O. (2020), "Technology acceptance theories and factors influencing artificial intelligence-based intelligent products", Telematics and Informatics, Vol. 47, in press.
Thye, S.R. Yoon, J. and Lawler, E. (2002), "The theory of relational cohesion: review of a research program", from Cornell University, ILR School site, available at: http:// digitalcommons.ilr.cornell.edu/articles/1220 (accessed 07/ $11 / 20)$

Till, B.D. and Busler, M. (1998), "Matching products with endorsers: attractiveness versus expertise", Fournal of Consumer Marketing, Vol. 15 No. 6, pp. 576-586.

Van Doorn, J., Lemon, K.N., Mittal, V., Nass, S., Pick, D., Pirner, P. and Verhoef, P.C. (2010), "Customer engagement behavior: theoretical foundations and research directions", Fournal of Service Research, Vol. 13 No. 3, pp. 253-266.

Ward, T. and Dagger, T.S. (2007), "The complexity of relationship marketing for service customers", fournal of Services Marketing, Vol. 21 No. 4, pp. 281-290.

Williams, J.J., Cote, J.A. and Buckley, M.R. (1989), "Lack of method variance in self-reported affect and perceptions at work: reality or artifact?", Fournal of Applied Psychology, Vol. 74 No. 3, pp. 462-468.

Wuenderlich, N.V., Heinonen, K., Ostrom, A.L., Patricio, L., Sousa, R., Voss, C. and Lemmink, J.G.A.M. (2015), "Futurizing' smart service: implications for service researchers and managers", fournal of Services Marketing, Vol. 29 Nos 6/7, pp. 442-447.

$\mathrm{Xu}, \mathrm{K}$. (2020), "Language, modality, and mobile media use experiences: social responses to smartphone cues in a taskoriented context", Telematics and Informatics, Vol. 48, pp. 1-13.

Yang, H. and Lee, H. (2019), "Understanding user behavior of virtual personal assistant devices", Information Systems and e-Business Management, Vol. 17 No. 1, pp. 65-87.

Yoon, J. and Lawler, E.J. (2006), "Relational cohesion model of organizational commitment", [Electronic version], from Cornell University, ILR School site, available at: http://digitalcommons. ilr.cornell.edu/articles/1216 (accessed 01/25/21)

Zheng, D. (2020), "Building residents commitment through tourism consumption: a relational cohesion lens", fournal of Destination Marketing and Management, Vol. 16, in press. 
Blanca Hernández-Ortega, Joaquin Aldas-Manzano and Ivani Ferreira

\section{Appendix 1}

Table A1. Studies on smart voice assistants

\begin{tabular}{|c|c|c|c|c|c|}
\hline Study & Approach & Technology & Explanatory variables & Dependent variables & Findings \\
\hline $\begin{array}{l}\text { (Fernandes and } \\
\text { Oliveira (2021) }\end{array}$ & User-based & $\begin{array}{l}\text { Digital voice } \\
\text { assistants }\end{array}$ & $\begin{array}{l}\text { Functional elements } \\
\text { (perceived ease of use, } \\
\text { perceived usefulness, } \\
\text { subjective social norms); } \\
\text { Social elements (perceived } \\
\text { humanness, perceived social } \\
\text { interactivity, perceived social } \\
\text { presence); Relational elements } \\
\text { (trust, rapport) }\end{array}$ & Acceptance & $\begin{array}{l}\text { Functional, social and relational } \\
\text { elements generate adoption. } \\
\text { Experience and need for human } \\
\text { interaction moderate the effect } \\
\text { of these factors. }\end{array}$ \\
\hline $\begin{array}{l}\text { Poushneh } \\
(2021)\end{array}$ & $\begin{array}{l}\text { Technology- } \\
\text { based }\end{array}$ & Voice assistants & $\begin{array}{l}\text { Perceived auditory sense; } \\
\text { Perceived auditory social } \\
\text { interaction; Perceived auditory } \\
\text { control; Surprise }\end{array}$ & $\begin{array}{l}\text { Consumers' trust in voice } \\
\text { assistants; Brand affect }\end{array}$ & $\begin{array}{l}\text { Perceived auditory sense } \\
\text { influences perceived auditory } \\
\text { control through auditory social } \\
\text { interactions with a voice } \\
\text { assistant that lead to brand } \\
\text { affect and consumers' trust in the } \\
\text { voice assistant. Moreover, } \\
\text { surprise acts as a repelling drive } \\
\text { that attenuates the effect of } \\
\text { perceived auditory control on } \\
\text { brand affect. }\end{array}$ \\
\hline $\begin{array}{l}\text { (Moriuchi } \\
(2020)\end{array}$ & User-based & Voice assistants & $\begin{array}{l}\text { Performance expectation; } \\
\text { Effort expectation; Perceived } \\
\text { risk; Social influence; } \\
\text { Anthropomorphism; } \\
\text { Engagement; Usage } \\
\text { experience }\end{array}$ & $\begin{array}{l}\text { Intention to re-use; Actual } \\
\text { use }\end{array}$ & $\begin{array}{l}\text { Anthropomorphism and } \\
\text { engagement play mediating roles } \\
\text { between usage experience with } \\
\text { the voice assistant and re-use } \\
\text { intentions. Intention to re-use } \\
\text { has a positive effect on actual } \\
\text { usage. }\end{array}$ \\
\hline $\begin{array}{l}\text { Pridmore and } \\
\text { Mols (2020) }\end{array}$ & User-based & $\begin{array}{l}\text { Household intelligent } \\
\text { personal assistants }\end{array}$ & $\begin{array}{l}\text { User expectations; Personal } \\
\text { and social motivations; } \\
\text { Structural circumstances; } \\
\text { Integrated routines }\end{array}$ & $\begin{array}{l}\text { Behavioral intentions; } \\
\text { User behavior }\end{array}$ & $\begin{array}{l}\text { Acceptance of the personal } \\
\text { assistant does not imply to } \\
\text { access to all data. Perceived } \\
\text { usefulness and effort are } \\
\text { antecedents of acceptance. }\end{array}$ \\
\hline $\begin{array}{l}\text { (McLean and } \\
\text { Osei-Frimpong } \\
(2019)\end{array}$ & User-based & $\begin{array}{l}\text { In-home voice } \\
\text { assistants }\end{array}$ & $\begin{array}{l}\text { Utilitarian benefits; Hedonic } \\
\text { benefits; Symbolic benefits; } \\
\text { Social benefits; Perceived } \\
\text { privacy risk of in-home voice } \\
\text { assistants }\end{array}$ & $\begin{array}{l}\text { Usage of in-home voice } \\
\text { assistants }\end{array}$ & $\begin{array}{l}\text { Individuals are motivated by the } \\
\text { (1) utilitarian benefits, (2) } \\
\text { symbolic benefits and (3) social } \\
\text { benefits provided by the voice } \\
\text { assistant. Additionally, the } \\
\text { research shows the role of } \\
\text { perceived privacy risks in } \\
\text { dampening and negatively } \\
\text { influencing the use of in-home } \\
\text { voice assistants. }\end{array}$ \\
\hline Moriuchi (2019) & User-based & Voice assistants & $\begin{array}{l}\text { Subjective norm; Perceived } \\
\text { usefulness; Perceived ease of } \\
\text { use; Localization; Consumer } \\
\text { engagement; Attitude }\end{array}$ & $\begin{array}{l}\text { Loyalty between } \\
\text { consumers and voice } \\
\text { assistants }\end{array}$ & $\begin{array}{l}\text { Subjective norms influence } \\
\text { perceived usefulness, ease of use } \\
\text { and engagement; Perceived } \\
\text { usefulness influences perceived } \\
\text { ease of use, attitude and } \\
\text { engagement; Perceived ease of } \\
\text { use influences attitude; Attitude } \\
\text { influences loyalty; Engagement } \\
\text { influences loyalty. }\end{array}$ \\
\hline
\end{tabular}


Blanca Hernández-Ortega, Joaquin Aldas-Manzano and Ivani Ferreira

Table A1.

\begin{tabular}{|c|c|c|c|c|c|}
\hline Study & Approach & Technology & Explanatory variables & Dependent variables & Findings \\
\hline $\begin{array}{l}\text { Pagani et al. } \\
(2019)\end{array}$ & $\begin{array}{l}\text { Technology- } \\
\text { based }\end{array}$ & Digital platforms & $\begin{array}{l}\text { Interface response mode: } \\
\text { Voice vs. Touch; Consumer } \\
\text { privacy concern; Personal } \\
\text { engagement }\end{array}$ & Brand trust & $\begin{array}{l}\text { There is a three-way interaction } \\
\text { such that the impact of privacy } \\
\text { concern on the relationship } \\
\text { between personal engagement } \\
\text { and trust depends on the nature } \\
\text { of the platform interaction (i.e., } \\
\text { touch vs. combined touch and } \\
\text { voice). Adding voice to the } \\
\text { platform interface has the } \\
\text { counterintuitive effect of } \\
\text { reducing engagement toward } \\
\text { that platform. }\end{array}$ \\
\hline $\begin{array}{l}\text { Yang and Lee } \\
(2019)\end{array}$ & User-based & $\begin{array}{l}\text { Virtual personal } \\
\text { assistant }\end{array}$ & $\begin{array}{l}\text { Perceived usefulness } \\
\text { (portability, automation, } \\
\text { content quality); Perceived } \\
\text { enjoyment (content quality; } \\
\text { visual attractiveness) }\end{array}$ & Behavioral intention & $\begin{array}{l}\text { Perceived usefulness and } \\
\text { enjoyment have a significant } \\
\text { impact on usage intention. } \\
\text { Content quality has the strongest } \\
\text { impact on perceived usefulness. } \\
\text { Visual attractiveness positively } \\
\text { affects perceived enjoyment. }\end{array}$ \\
\hline $\begin{array}{l}\text { Kowalczuk } \\
(2018)\end{array}$ & User-based & Smart speakers & $\begin{array}{l}\text { Technology optimism; System } \\
\text { diversity; System quality; } \\
\text { Perceived enjoyment; } \\
\text { Perceived usefulness; } \\
\text { Perceived ease of use; Risk }\end{array}$ & Behavioral intention & $\begin{array}{l}\text { Findings demonstrate that } \\
\text { perceived ease of use, perceived } \\
\text { usefulness, the quality and } \\
\text { diversity of a system, perceived } \\
\text { enjoyment, consumer's } \\
\text { technology optimism and risk } \\
\text { strongly affect the acceptance of } \\
\text { smart speakers. }\end{array}$ \\
\hline
\end{tabular}


Blanca Hernández-Ortega, Joaquin Aldas-Manzano and Ivani Ferreira

\section{Appendix 2. Confirmatory factor analysis}

Table A2 Measurement model reliability and convergent validity

\begin{tabular}{|c|c|c|c|c|c|c|}
\hline Construct & Item & Factor loading & $t$-value & $\mathrm{R}^{2}$ & CRC & AVE \\
\hline \multirow[t]{3}{*}{ INTERACTION FREQUENCY } & FREQ_1 & 0.826 & 23.550 & 0.683 & 0.820 & 0.603 \\
\hline & FREQ_2 & 0.789 & 18.749 & 0.623 & & \\
\hline & FREQ_3 & 0.711 & 21.364 & 0.506 & & \\
\hline \multirow[t]{3}{*}{ PLEASURE BASED-SATISFACTION } & SAT_1 & 0.913 & 21.908 & 0.834 & 0.919 & 0.790 \\
\hline & SAT_2 & 0.896 & 24.298 & 0.802 & & \\
\hline & SAT_3 & 0.857 & 22.197 & 0.734 & & \\
\hline \multirow[t]{3}{*}{ INTEREST } & INT_1 & 0.905 & 34.166 & 0.818 & 0.899 & 0.749 \\
\hline & INT_2 & 0.880 & 37.123 & 0.775 & & \\
\hline & INT_3 & 0.808 & 25.608 & 0.653 & & \\
\hline \multirow[t]{6}{*}{ RELATIONAL COHESION } & RECH_1 & 0.777 & 28.299 & 0.604 & 0.955 & 0.699 \\
\hline & RECH_2 & 0.823 & 22.887 & 0.677 & & \\
\hline & RECH_3 & 0.854 & 25.924 & 0.729 & & \\
\hline & RECH_4 & 0.887 & 27.893 & 0.787 & & \\
\hline & RECH_5 & 0.852 & 25.884 & 0.725 & & \\
\hline & RECH_6 & 0.846 & 26.064 & 0.715 & & \\
\hline \multirow[t]{4}{*}{ USER PURCHASES } & PUR_1 & 0.894 & 21.284 & 0.799 & 0.934 & 0.779 \\
\hline & PUR_2 & 0.904 & 21.742 & 0.817 & & \\
\hline & PUR_3 & 0.895 & 22.999 & 0.802 & & \\
\hline & PUR_4 & 0.835 & 22.707 & 0.697 & & \\
\hline \multirow[t]{4}{*}{ USER KNOWLEDGE } & KNO_1 & 0.888 & 36.252 & 0.789 & 0.962 & 0.863 \\
\hline & KNO_2 & 0.933 & 40.511 & 0.871 & & \\
\hline & KNO_3 & 0.948 & 42.792 & 0.898 & & \\
\hline & KNO_4 & 0.946 & 45.047 & 0.896 & & \\
\hline \multirow[t]{4}{*}{ USER REFERENCE } & REF_1 & 0.872 & 22.101 & 0.761 & 0.917 & 0.736 \\
\hline & REF_2 & 0.896 & 23.435 & 0.804 & & \\
\hline & REF_3 & 0.897 & 26.094 & 0.805 & & \\
\hline & REF_4 & 0.758 & 23.749 & 0.575 & & \\
\hline \multicolumn{7}{|c|}{$B B N F I=0.916 ; T L I=0.927 ; I F I=0.937 ; C F I=0.937 ;$} \\
\hline
\end{tabular}


Blanca Hernández-Ortega, Joaquin Aldas-Manzano and Ivani Ferreira

Table A3. Measurement model discriminant validity

\begin{tabular}{|c|c|c|c|c|c|c|c|}
\hline Panel a & $\mathrm{F} 1$ & $\mathrm{~F} 2$ & F3 & F4 & F5 & F6 & F7 \\
\hline F1. Frequency & 0.78 & 0.78 & 0.69 & 0.80 & 0.77 & 0.68 & 0.72 \\
\hline F2. P. Satisfaction & 0.72 & 0.89 & 0.58 & 0.80 & 0.88 & 0.53 & 0.76 \\
\hline F3. Interest & 0.61 & 0.50 & 0.87 & 0.79 & 0.50 & 0.79 & 0.69 \\
\hline F4. Relation cohesion & 0.74 & 0.76 & 0.74 & 0.84 & 0.74 & 0.76 & 0.77 \\
\hline F5. User purchases & 0.70 & 0.84 & 0.42 & 0.68 & 0.88 & 0.51 & 0.87 \\
\hline F6. User knowledge & 0.65 & 0.69 & 0.63 & 0.72 & 0.81 & 0.93 & 0.69 \\
\hline F7. User reference & 0.61 & 0.45 & 0.73 & 0.71 & 0.43 & 0.63 & 0.86 \\
\hline Panel $b$ & F1 & $F 2$ & F3 & F4 & F5 & F6 & $F 7$ \\
\hline F1. Frequency & 1.00 & & & & & & \\
\hline F2. P. Satisfaction & 0.72 & 1.00 & & & & & \\
\hline F3. Interest & 0.66 & 0.52 & 1.00 & & & & \\
\hline F4. Relation cohesion & 0.77 & 0.76 & 0.76 & 1.00 & & & \\
\hline F5. User purchases & 0.71 & 0.84 & 0.47 & 0.69 & 1.00 & & \\
\hline F6. User knowledge & 0.64 & 0.46 & 0.74 & 0.73 & 0.46 & 1.00 & \\
\hline F7. User reference & 0.69 & 0.70 & 0.68 & 0.75 & 0.83 & 0.67 & 1.00 \\
\hline
\end{tabular}

Notes: (panel a): The diagonal represents the squared root of the average variance extracted. Below the diagonal, elements represent correlations among constructs. Upper triangle: upper limit of the $99 \%$ confidence interval for the estimation of the factor correlations Note (panel b): HTMT ratios

\section{Corresponding author}

Blanca Hernández-Ortega can be contacted at:

bhernand@unizar.es

For instructions on how to order reprints of this article, please visit our website:

www.emeraldgrouppublishing.com/licensing/reprints.htm

Or contact us for further details: permissions@emeraldinsight.com 